\title{
Avian pathogenic Escherichia coli (APEC) infection alters bone marrow transcriptome in chickens
}

\author{
Hongyan Sun ${ }^{1}$, Peng Liư ${ }^{2}$ Lisa K. Nolan ${ }^{3}$ and Susan J. Lamont ${ }^{1 *}$
}

\begin{abstract}
Background: Avian pathogenic Escherichia coli (APEC) is a major cause of disease impacting animal health. The bone marrow is the reservoir of immature immune cells; however, it has not been examined to date for gene expression related to developmental changes (cell differentiation, maturation, programming) after APEC infection. Here, we study gene expression in the bone marrow between infected and non-infected animals, and between infected animals with mild (resistant) versus severe (susceptible) pathology, at two times post-infection.
\end{abstract}

Results: We sequenced 24 bone marrow RNA libraries generated from the six different treatment groups with four replicates each, and obtained an average of 22 million single-end, 100-bp reads per library. Genes were detected as differentially expressed (DE) between APEC treatments (mild pathology, severe pathology, and mock-challenged) at a given time point, or DE between 1 and 5 days post-infection (dpi) within the same treatment group. Results demonstrate that many immune cells, genes and related pathways are key contributors to the different responses to APEC infection between susceptible and resistant birds and between susceptible and non-challenged birds, at both times post-infection. In susceptible birds, lymphocyte differentiation, proliferation, and maturation were greatly impaired, while the innate and adaptive immune responses, including dendritic cells, monocytes and killer cell activity, TLR- and NOD-like receptor signaling, as well as T helper cells and many cytokine activities, were markedly enhanced. The resistant birds' immune system, however, was similar to that of non-challenged birds.

Conclusion: The DE genes in the immune cells and identified signaling models are representative of activation and resolution of infection in susceptible birds at both post-infection days. These novel results characterizing transcriptomic response to APEC infection reveal that there is combinatorial activity of multiple genes controlling myeloid cells, and B and T cell lymphopoiesis, as well as immune responses occurring in the bone marrow in these early stages of response to infection.

Keywords: RNAseq, APEC, Bone marrow, Transcriptome, Immune response

\section{Background}

Avian pathogenic Escherichia coli (APEC) can cause colibacillosis due to immunosuppression and damage of the immune system $[1,2]$. Infection is typically initiated in the respiratory tract by inhalation of fecal dust from which it can gain access to the bloodstream and immune organs, causing septicemia, pericarditis, and mortality [3, 4]. Similar phylogenic backgrounds and certain virulence genes are present in both APEC and human extra-intestinal pathogenic Escherichia coli (ExPEC) [5]. Thus, poultry products contaminated with APEC are a potential source

\footnotetext{
* Correspondence: sjlamont@iastate.edu

'Department of Animal Science, lowa State University, Ames, lowa 50011, USA
} Full list of author information is available at the end of the article of foodborne ExPEC infection to humans, posing a threat to human health [6-9]. Although vaccination offers one route to control APEC, many vaccines may only be effective against homologous APEC challenge [10, 11]. Consequently, a more comprehensive understanding of chicken responses to APEC will facilitate the improvement of control strategies, vaccine development, and human health.

Bone marrow, the source of pluripotent hematopoietic stem cells, is a reservoir for two main categories of white blood cells, the lymphoid and myeloid lineages [12]. The lymphoid lineage differentiates into $\mathrm{B}, \mathrm{T}$, and natural killer cells, while the myeloid lineage develops into macrophages, granulocytes, mast cells, and dendritic cells (DCs) [12-14]. All these cells play critical roles in innate 
and adaptive immune responses. Genome-wide gene expression profiling of immune organs or cells has become a major method to simultaneously compare the expression levels of hundreds of thousands of genes between different conditions [15-18].

Bone marrow is an excellent tissue source for genomic scale gene expression profiling in APEC infection because it provides primordial cells that have not been influenced by developmental cytokines and other factors that would be present in the lymphoid organs. The study of bone marrow, therefore, offers new avenues to elucidate a comprehensive picture of the immune mechanism the primary lymphoid organ depends on to respond to APEC infection at the early transcriptional level. Here, we study gene expression in the bone marrow between infected and non-infected animals, and between infected animals with mild (resistant) vs. severe (susceptible) pathology, at two times post-infection.

\section{Methods}

\section{Ethics statement}

All animal care and experimental procedures were reviewed and approved by the Animal Care and Use Committee (\#11-07-6460-G) of the Research Animal Resources Center at Iowa State University.

\section{Experimental design}

A total of 360 commercial broiler male chicks, obtained at day of hatch from the same commercial supplier, were studied in six replicated experiments. For each replicate, 48 male meat-type (broiler) chickens at 4 weeks of age were challenged with $0.1 \mathrm{ml}$ APEC $\mathrm{O} 1$ introduced by the intra-air sac route, and 12 birds in a control group were mock-challenged with $0.1 \mathrm{ml}$ of phosphate buffered saline (PBS). Birds were euthanized and bone marrow was harvested at 1 and 5 days post-infection (dpi), from half of the birds at each time point. The sample collection times were chosen to include the day of maximum symptoms (5 dpi) based on previous studies of coauthor Nolan's group with the same bacteria [9] and one early day ( $1 \mathrm{dpi})$ to assess the immediate, early changes in gene expression occurring in the tissues. A veterinary pathologist visually inspected and scored the severity of the lesions in three tissues - air sacs, pericardium, and liver - according to the standard pathology scoring system described by Peighambari et al. [19]. Scores for pericardium and liver were $0-2$, for air sacs were $0-3$. Birds with summed lesion scores of $0-3$ were classified as the "mild" (resistant) infected group and those with summed scores of 4-7 were classified as the "severe" (susceptible) infected group. Birds with intermediate pathology scores were not included in the transcriptome study. In total, six treatments resulted across challenge status, day postinfection necropsy, and pathology level (Fig. 1). The APEC O1 strain is highly virulent in birds and its genome has been completely sequenced [9]. Detailed information on the APEC O1 strain and related procedures have been previously published $[20,21]$.

\section{Total RNA extraction}

Four birds (one from each of four replicates) from each of the six conditions were selected, resulting in 24 samples used for RNAseq. The RNA samples were isolated using the Ambion MagMax-96 Kit (AM1839) (Applied Biosystems, Foster City, CA) and immediately stored at $-80{ }^{\circ} \mathrm{C}$. All extraction procedures were performed according to

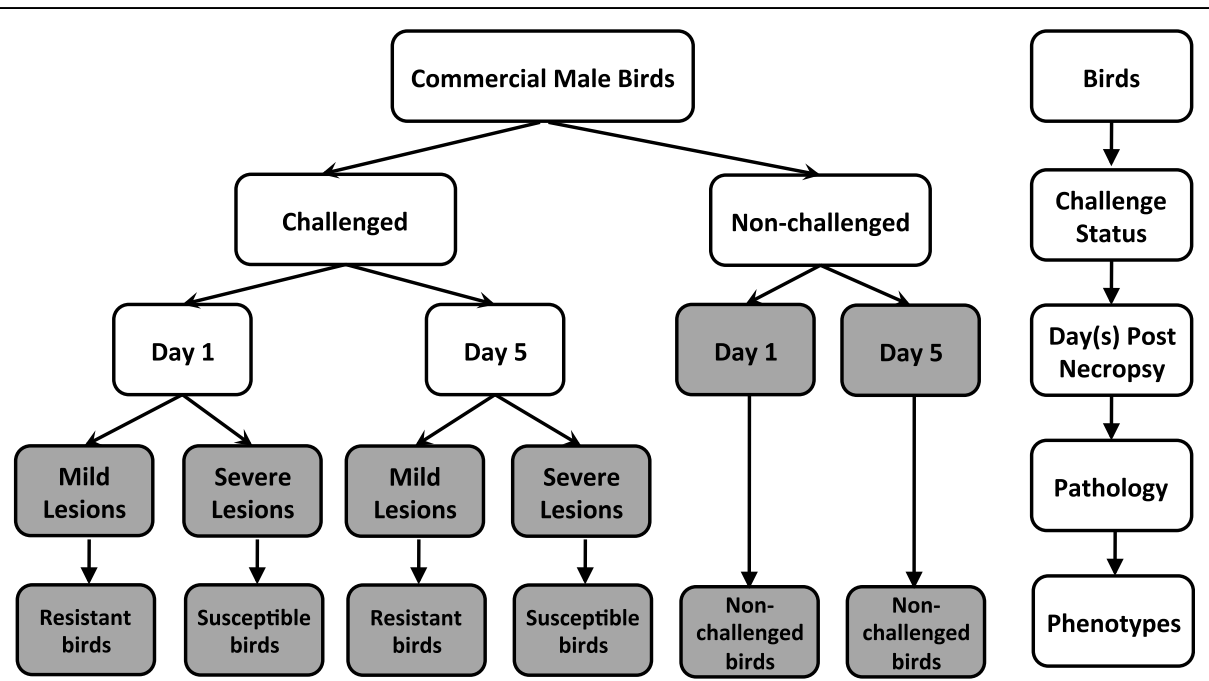

Fig. 1 Experimental design. Chicks were divided into each of three different conditions: APEC challenge status, tissue harvest time, and pathology level. Based on the severity of lesions in liver, pericardium, and air-sac scored at necropsy, the challenged birds were assigned to either mild or severe pathology categories, representing resistant and susceptible phenotypes, respectively. Birds in six treatments total were studied: day 1 resistant, day 1 susceptible, day 5 resistant, day 5 susceptible, day 1 non-infected, and day 5 non-infected 
manufacturer's recommendations. A NanoDrop ND-1000 UV-vis Spectrophotometer (NanoDrop Technologies Inc., Wilmington, DE, USA) was used to quantify the RNA. In addition, the quality of RNA was tested using the Agilent 2100 Bioanalyser (Agilent Technologies). The RNA Integrity Number (RIN) was greater than 9.0 for all samples.

\section{cDNA library construction and illumina deep sequencing}

The initial total RNA was converted into a cDNA sequencing library through the Illumina TruSeq ${ }^{\circ}$ RNA Sample Preparation v2 Kit following the manufacturer's instructions (Protocol: \#15026495, May 2012). First, 0.1 - 4 g total RNA was purified using Poly-T oligo-attached magnetic beads to obtain the mRNA fragments. Next, the first-strand cDNA was synthesized from the mRNA fragments. Finally, second-strand cDNA synthesis, end repair, 3 ' end adenylation, and adapter ligation were performed and PCR amplification was conducted. The cDNA libraries were validated and quantified using a Qubit $^{\circ}$ Quantitation Platform and an HS dsDNA kit (Invitrogen, Paisley, $\mathrm{UK})$. The $24 \mathrm{cDNA}$ libraries were individually generated from 24 samples. One library from each of the six treatments was pooled into one lane to sequence. Thus, four lanes were used to sequence the $24 \mathrm{cDNA}$ libraries through the Illumina ${ }^{\circ}$ HiSeq 2000 at the Iowa State University (ISU) DNA facility.

The image files were converted into sequences using Illumina Software to obtain $100 \mathrm{bp}$ single-end reads during sequencing of fragment clusters.

\section{RNAseq analysis}

For each of the sequencing reads, low-quality bases (Sanger base quality $<20$ ) of 3' ends were first trimmed using in-house perl scripts and the sequencing adapters were then trimmed using Fastx toolkit (version 0.0.13) software. Quality of the reads was determined by FastQC software (version 0.10.1). All Illumina single-end reads of 24 samples from six treatments were mapped separately to Ensembl Gallus gallus 4.0 reference genome by TopHat software (version 2.0.9) and Bowtie (version 2.1.0) using default parameters. The HTseq package (version 0.5.4p3) in Python was used to calculate the number of aligned reads per exon through Ensembl annotation of the chicken genome. The number of read counts per gene was identified in the output file by Ensembl gene ID. The RNAseq data can be obtained from the Gene Expression Omnibus (GEO) database with the accession number GSE67302.

Qlucore Omics Explorer (v3.0) was used to perform principle component analysis (PCA). The detected genes (count number $>1$ ) from the 24 samples were $\log _{2}$ transformed and subjected to normalization (mean $=0$ and variance $=1$ ). The Bioconductor package edgeR (version
3.0.8) developed in $\mathrm{R}$ software (version 2.15.3) was used to identify the differentially expressed (DE) genes. Trimmed mean of M-values (TMM) normalization method [22] was performed in edgeR to normalize the data across libraries. Generalized linear models based on negative binomial distributions were fit to the data using edge $\mathrm{R}$, and the model includes treatment and replicate effects. The Benjamini-Hochberg (BH) method was applied to control the false discovery rate (FDR) [23]. A gene was designated $\mathrm{DE}$ if its fold change of expression was above 1.5 while FDR was controlled at $5 \%$.

Cell type enrichment (CTen) was used to analyze the cell-type specificity for the RNAseq data to detect changes in the cellular demographics [24]. The cell type enrichment analysis was measured by the enrichment score, the $-\log _{10}$ of the BH adjusted $p$ values [25]. The GOseq package (version 1.10.0) was used to detect the enrichment of gene ontologies (GO) among the list of DE genes. For heatmap pathway analysis, bayesian likelihood ratio test was used to determine the goodness-of-fit. Then, the ratio was transformed to a z-score test statistic (Bayesian z-score) to permit comparison of scores across all pathways.

\section{Quantitative PCR (qPCR) and statistical analysis}

Fifteen genes, ADA, BLNK, CD3D, CD28, CD40, CD3Z, IFNG, IL1, IL7, IL8, IL18, LIG4, MD2, NOD1, TLR4, were selected to confirm RNAseq results. Criteria for gene selection were based on immune response function and significance in the RNAseq study. 28S, a housekeeping gene, was utilized to normalize the starting concentration of RNA. Primer sequences for the fifteen selected genes were designed by using sequences from NCBI and PRIMER3 [26]. Primer sequence details are provided in Additional file 1: Table S1. All genes assays were run in triplicate for the same individual samples as the RNAseq. qPCR was conducted using QuantiTect SYBR Green RT-PCR kit (Qiagen Inc., Valencia, CA). The adjusted cycle threshold $(\mathrm{Ct})$ values were calculated using the equation: $40-$ [Ct sample gene mean $+(\mathrm{Ct} 28 \mathrm{~S}$ median - Ct $28 \mathrm{~S}$ mean)(slope of sample gene/slope of 28S)]. The qPCR data were analyzed using JMP 8.0.2 statistical software (SAS Institute Inc., Cary, NC). The mRNA expression levels were measured as the mean adjusted $\mathrm{Ct}$ values of each triplicate sample. The analysis model used in the ANOVA analysis of JMP 8.0.2 was as following: $\mathrm{Y}=$ $\mu+$ challenge + day collection + replicate + e. Challenge, day collection, and replicate were considered as fixed effects. e was the random effect. Student's t test of JMP 8.0.2 was performed to test the significant difference between different contrasts. The significance level was set at 0.05 . Fold change was measured by the equation: $2^{\text {(adjusted } \mathrm{Ct}}$ value of treatment A - adjusted Ct value of treatment B). Gene expression fold change and significance in $\mathrm{QPCR}$ were used to compare with RNAseq for different contrasts. 


\section{Results}

\section{Transcriptome sequence}

Twenty-four individual samples (4 different individuals of 6 treatments) were analyzed by RNAseq. RNA sequencing resulted in 11 to 40 million single-end raw reads of $100 \mathrm{bp}$ per sample (Table 1). After alignment, an average of $80 \%$ of the reads, with $5 \%$ representing multiple mapping, were mapped to the chicken reference transcriptome (Table 1). There are 17,108 annotated chicken genes in the Ensembl database (http://useast.ensembl.org/biomart/martview/174 4c16506e92aabbac0907509c58539). On average, 14,388 chicken genes were detected for an individual, accounting for about $84 \%$ of all 17,108 annotated chicken genes in the database (Table 1). Among these detected unique genes, there were 2,404 novel genes, mainly on chromosomes 1,2 , $4,3, \mathrm{Z}$, and 5 in decreasing number. A total of 9,569 genes were included in the statistical analysis by retaining only genes that were detected with the read count above 2 counts per million for each sample in at least one treatment group.

\section{Pathology level and sample similarity}

After infection, the birds exhibited normally distributed summed pathology scores (Fig. 2). For the RNAseq, we used birds of high and low pathology scores, to represent disease-susceptible and disease-resistant phenotypes, respectively. Birds with 0 to1 lesion score (average 0.375) as resistant phenotype, and birds with 6 to 7 lesion score (average 6.625) as the susceptible phenotype were used. For the RNAseq dataset, PCA was used to identify sample similarity among the six treatments (Fig. 3). The susceptible birds (severe pathology) at both time points were separately clustered. The other four treatments were intermingled in the PCA. Results clearly indicate that challenged-susceptible birds exhibit transcriptomic changes that are distinct from the challenged-resistant and non-challenged birds, and that this is also influenced by time post-infection. However, there is very little difference in transcriptomes between challenged-resistant and nonchallenged birds.

Table 1 Summary of numbers of sequencing reads, mapped reads, mapping rate, detected genes and transcriptome coverage

\begin{tabular}{|c|c|c|c|c|c|c|c|}
\hline \multicolumn{3}{|c|}{ Treatments } & \multirow[t]{2}{*}{ Raw reads } & \multirow[t]{2}{*}{ Mapped reads } & \multirow[t]{2}{*}{$\%$ of reads Mapped } & \multirow[t]{2}{*}{ Detected genes } & \multirow[t]{2}{*}{ Transcriptome coverage } \\
\hline dpi & Phenotype & Bird \# & & & & & \\
\hline 1 & Non-challenged & 1 & $40,958,949$ & $32,154,546$ & $80.3 \%$ & 14,986 & $87.59 \%$ \\
\hline 1 & Non-challenged & 2 & $17,774,235$ & $13,758,514$ & $78.7 \%$ & 14,275 & $83.44 \%$ \\
\hline 1 & Non-challenged & 3 & $17,409,364$ & $13,812,510$ & $80.7 \%$ & 14,140 & $82.65 \%$ \\
\hline 1 & Non-challenged & 4 & $38,557,156$ & $26,754,843$ & $70.6 \%$ & 14,859 & $86.85 \%$ \\
\hline 1 & Resistant & 1 & $21,110,683$ & $15,919,755$ & $78.6 \%$ & 14,432 & $84.36 \%$ \\
\hline 1 & Resistant & 2 & $19,457,693$ & $14,734,512$ & $79.8 \%$ & 14,374 & $84.02 \%$ \\
\hline 1 & Resistant & 3 & $31,249,434$ & $24,654,203$ & $80.4 \%$ & 14,936 & $87.30 \%$ \\
\hline 1 & Resistant & 4 & $26,426,437$ & $21,574,698$ & $83.0 \%$ & 14,640 & $85.57 \%$ \\
\hline 1 & Susceptible & 1 & $26,940,892$ & $20,423,349$ & $79.3 \%$ & 14,759 & $86.27 \%$ \\
\hline 1 & Susceptible & 2 & $16,227,837$ & $11,585,446$ & $79.1 \%$ & 13,954 & $81.56 \%$ \\
\hline 1 & Susceptible & 3 & $23,554,069$ & $18,481,538$ & $79.8 \%$ & 14,713 & $86.00 \%$ \\
\hline 1 & Susceptible & 4 & $19,045,548$ & $15,352,573$ & $82.2 \%$ & 14,409 & $84.22 \%$ \\
\hline 5 & Non-challenged & 1 & $40,113,450$ & $31,164,137$ & $79.5 \%$ & 14,966 & $87.48 \%$ \\
\hline 5 & Non-challenged & 2 & $15,799,657$ & $12,039,801$ & $80.0 \%$ & 13,947 & $81.52 \%$ \\
\hline 5 & Non-challenged & 3 & $20,791,304$ & $16,735,997$ & $81.8 \%$ & 14,235 & $83.21 \%$ \\
\hline 5 & Non-challenged & 4 & $27,189,817$ & $21,665,457$ & $81.1 \%$ & 14,553 & $84.95 \%$ \\
\hline 5 & Resistant & 1 & $20,286,505$ & $14,862,432$ & $79.8 \%$ & 14,296 & $83.56 \%$ \\
\hline 5 & Resistant & 2 & $11,761,420$ & $8,652,658$ & $80.0 \%$ & 13,543 & $79.16 \%$ \\
\hline 5 & Resistant & 3 & $18,361,293$ & $14,341,042$ & $80.2 \%$ & 14,281 & $83.48 \%$ \\
\hline 5 & Resistant & 4 & $16,590,846$ & $13,386,031$ & $80.7 \%$ & 14,038 & $82.06 \%$ \\
\hline 5 & Susceptible & 1 & $22,585,434$ & $17,629,308$ & $80.7 \%$ & 14,467 & $84.56 \%$ \\
\hline 5 & Susceptible & 2 & $11,789,716$ & $8,534,110$ & $78.7 \%$ & 13,839 & $80.89 \%$ \\
\hline 5 & Susceptible & 3 & $17,874,004$ & $13,601,653$ & $77.9 \%$ & 14,495 & $84.73 \%$ \\
\hline 5 & Susceptible & 4 & $15,429,659$ & $12,406,170$ & $82.0 \%$ & 14,163 & $82.79 \%$ \\
\hline
\end{tabular}




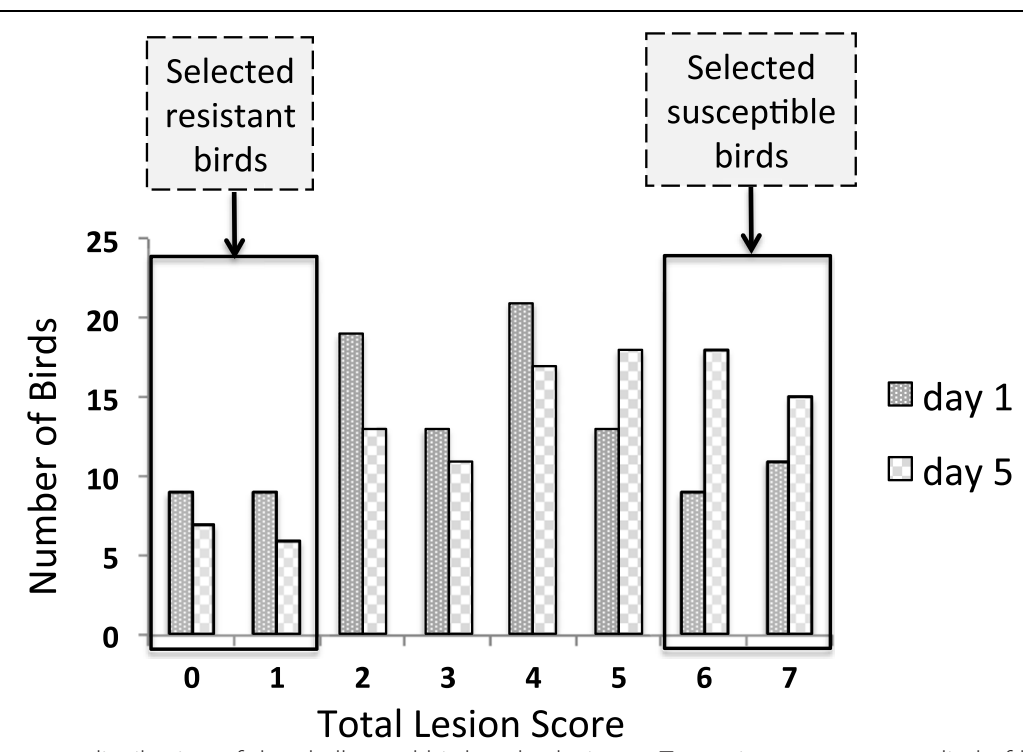

Fig. 2 Summation of lesion score distribution of the challenged birds at both times. Transcriptomes were studied of birds lesion scores of 0-1 (resistant) and 6-7 (susceptible). The average lesion scores of the four replicates resistant and susceptible birds is 0.375 and 6.625 , respectively

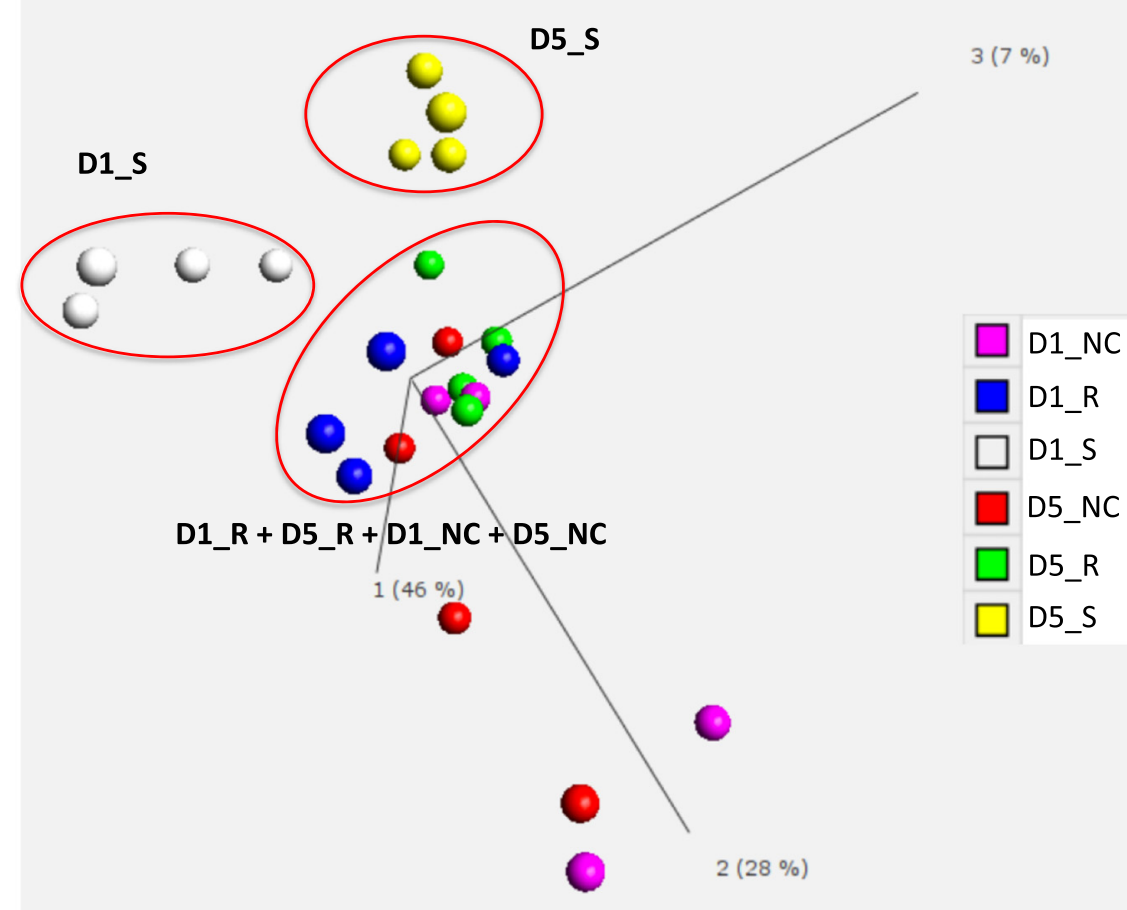

Fig. 3 Principal component analysis (PCA) of transcriptome of all 24 RNAseq libraries. Across the complete dataset, 20.46\% (3501/17108) genes were differentially expressed with the false discovery rate $(F D R)<0.05$ and fold change $>1.5$. Each point indicates one RNAseq library. The susceptible birds at the two time points clustered separately. The other four treatments, however, were clustered together. Abbreviations: D1_NC, day 1 non-challenged birds; D1_R, day 1 resistant birds; D1_S, day 1 susceptible birds; D5_NC, day 5 non-challenged birds; D5_R, day 5 resistant birds; D5_S, day 5 susceptible birds 


\section{DE genes in bone marrow}

Differences in treatment groups associated with pathology were detected by contrasts of treatment groups within each time point, while differences associated with time effects were detected by contrasts of the two time points within each treatment group. Consequently, nine total contrasts were generated. Figure 4 shows the numbers of shared and unique DE genes based on treatment effects within time and time effects within treatment.

At $1 \mathrm{dpi}$, in comparison to non-challenged birds, hundreds of DE genes were detected in resistant birds $(\mathrm{N}=$ $189)$ and in susceptible birds $(\mathrm{N}=885)$. The numbers of up-regulated DE genes were far greater than the numbers down-regulated. At $1 \mathrm{dpi}$, only 5 significantly DE genes were co-expressed in three of the contrasts (Fig. 4a). There were $162 \mathrm{DE}$ genes shared between susceptible vs. resistant birds and susceptible vs. non-challenged birds on day 1, while only small numbers of DE genes were shared in other contrasts (Fig. 4a). These results suggest that early after infection, $1 \mathrm{dpi}$, the bone marrow gene expression of challenged-susceptible birds was similar to that of challenged-resistant birds, and that challenged birds differed significantly from non-challenged birds.

At $5 \mathrm{dpi}$, the bone marrow transcriptome of resistant birds was very similar to non-challenged birds, with only two genes detected as DE between the two conditions (Fig. 4b). Between the contrasts of susceptible vs. nonchallenged birds and of susceptible vs. resistant birds, $59 \%(1,371 / 2,946)$ of DE genes were in common. There were 1071 and 142 unique DE genes in susceptible vs. non-challenged birds and susceptible vs. resistant birds, respectively, on day 5 (Fig. 4b). Generally, the numbers of DE genes in resistant vs. non-challenged birds decreased over time, while the numbers of DE genes increased over time in the susceptible vs. non-challenged and the susceptible vs. resistant contrasts (Fig. $4 \mathrm{a}$ and b). These results suggest that the bone marrow transcriptome of challenged-resistant birds was returning to a homeostatic state by $5 \mathrm{dpi}$. Challenged-susceptible birds continued to diverge from both challenged-resistant and non-challenged birds as post-challenge time progressed from 1 dpi to $5 \mathrm{dpi}$.

There was little difference $(\mathrm{N}=9)$ in the bone marrow transcriptome of non-challenged birds at 5 vs. 1 dpi. However, both infected treatment groups (resistant and susceptible) had large numbers of DE genes $(\mathrm{N}=105 ; \mathrm{N}=1371$ respectively) over time, especially the susceptible birds (Fig. 4c). Of the 1,371 DE genes, $97 \%(1,334)$ of them were unique in susceptible birds. These results demonstrate that challenged-susceptible birds have a unique gene expression profile that diverges over time from that of challenged-resistant and non-challenged birds.

\section{DE gene cell specific activity and GO terms assignments}

The four contrasts with the largest numbers of DE genes were used to analyze cell types with the online tool CTen with an enrichment score $>2$ as the cutoff for significance. Immune response cells were highly enriched: several different types of lymphocytes, whole blood, CD14+ monocytes, CD33+ myeloid cells, bone marrow, and DCs, all of which were detected in the three contrasts: susceptible vs. non-challenged at $5 \mathrm{dpi}$, susceptible vs. resistant at $5 \mathrm{dpi}$, and 5 dpi vs. 1 dpi in susceptible birds (Fig. 5). The different types of lymphocytes include CD4+ T cells, CD8+

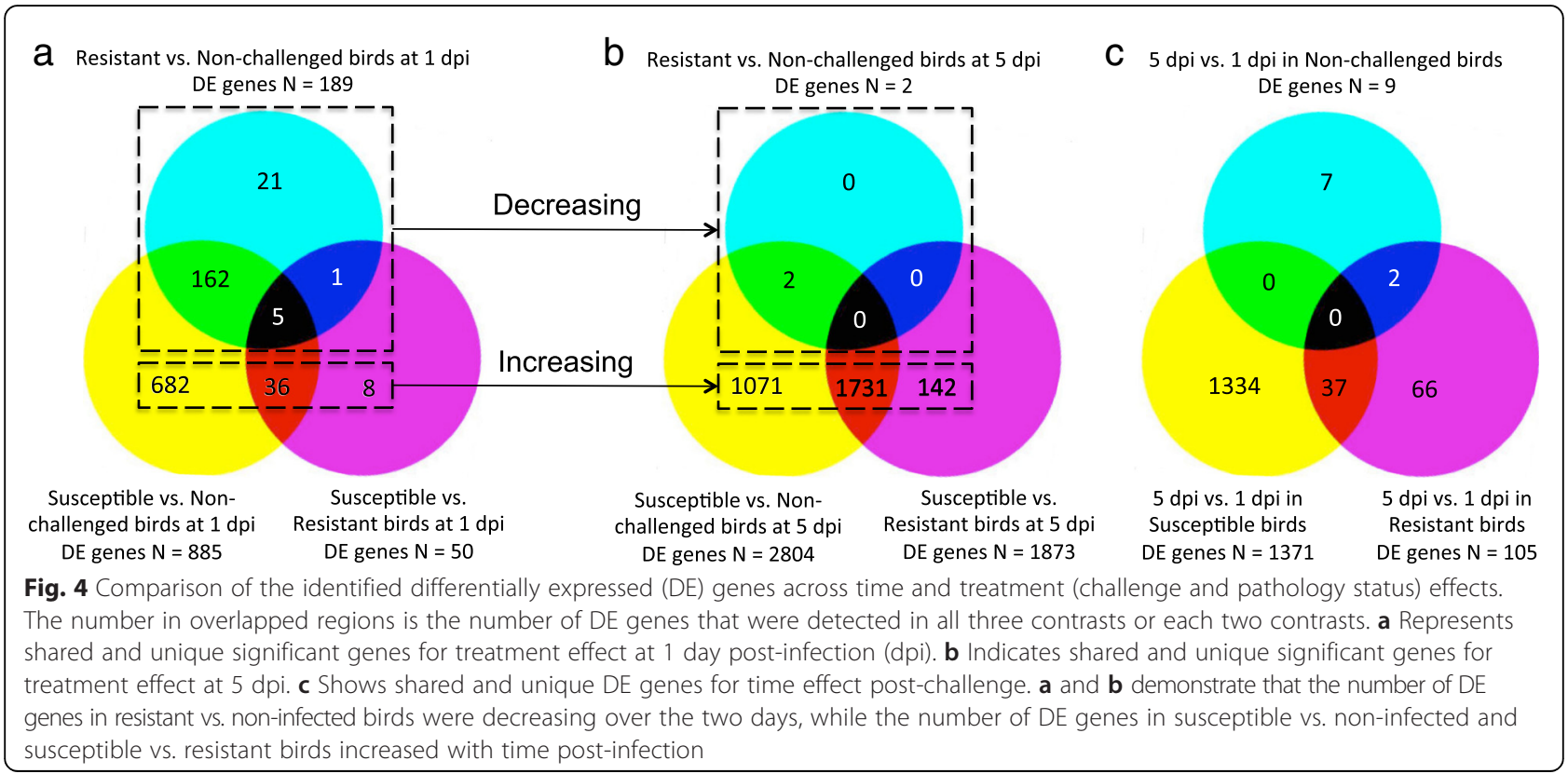




\section{Biological Process Enrichment}

Susceptible birds vs. Non-challenged birds at $5 \mathrm{dpi}$ (DE genes $\mathrm{N}=2804$; $\mathrm{BH}$-adjusted $\mathrm{P}$-value < 0.05 )

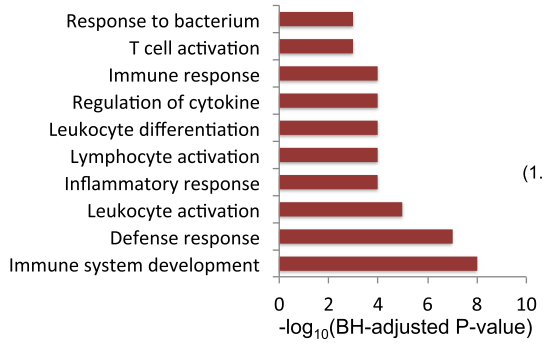

Susceptible birds vs. Resistant birds at $5 \mathrm{dpi}$ (DE genes N=1873; $\mathrm{BH}$-adjusted $\mathrm{P}$-value < 0.05)

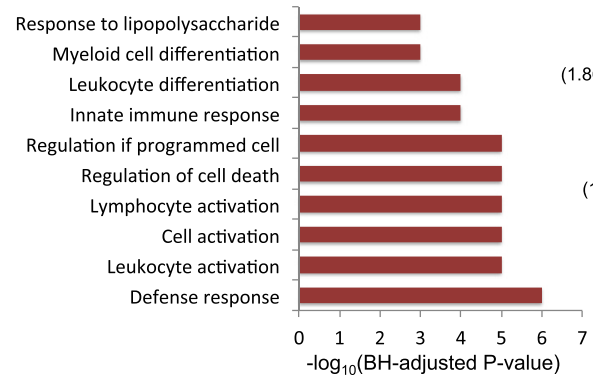

Susceptible birds vs. Non-challenged birds at $1 \mathrm{dpi}$ ( $\mathrm{DE}$ genes $\mathrm{N}=885$; $\mathrm{BH}$-adjusted $\mathrm{P}$-value < 0.05 )

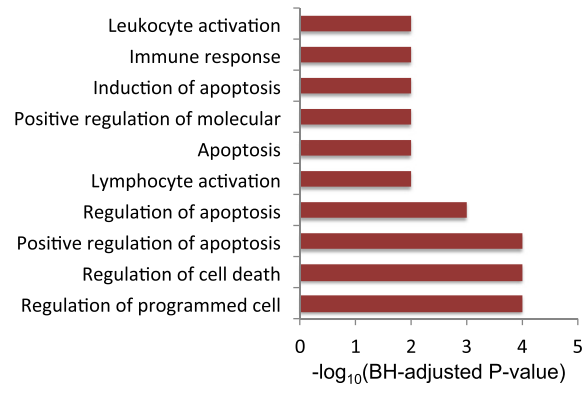

5 dpi vs. 1 dpi in susceptible birds

(DE genes $\mathrm{N}=1371$; $\mathrm{BH}$-adjusted $\mathrm{P}$-value < 0.05)

Positive regulation of immune

Protein kinase activity Leukocyte activation Cell activation Src homology-3 domain Regulation of cell death Regulation of programmed cell

Regulation of apoptosis

Innate immune response Defense response

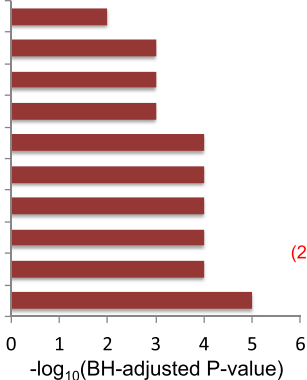

Cell-type Enrichment

$-\log _{10}(\mathrm{BH}$-adjusted $\mathrm{P}$-value $)$

Susceptible birds vs. Non-challenged birds at $5 \mathrm{dpi}$ $(4.34)$
$\mathrm{CD} 56+\mathrm{NK}$ Cels

(4.14) Lymph Node BDCA4+ Dentritic Cells (7.23)

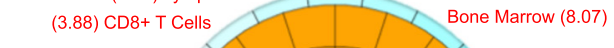

(3.74) CD4+ T Cells CD33+ Myeloid (16.12)

(2.38) CD19+ B cells

82) CD71+ Early Erythroid

roid

(1.72) Lung

(1.28) Cardiac Myocytes

(1.14) Smooth Muscle

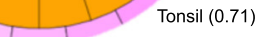

(1.03) Placenta
$\begin{gathered}\text { Adipocyte } \\ (1.02)\end{gathered}$

Susceptible birds vs. Resistant birds at $5 \mathrm{dpi}$ (4.97)

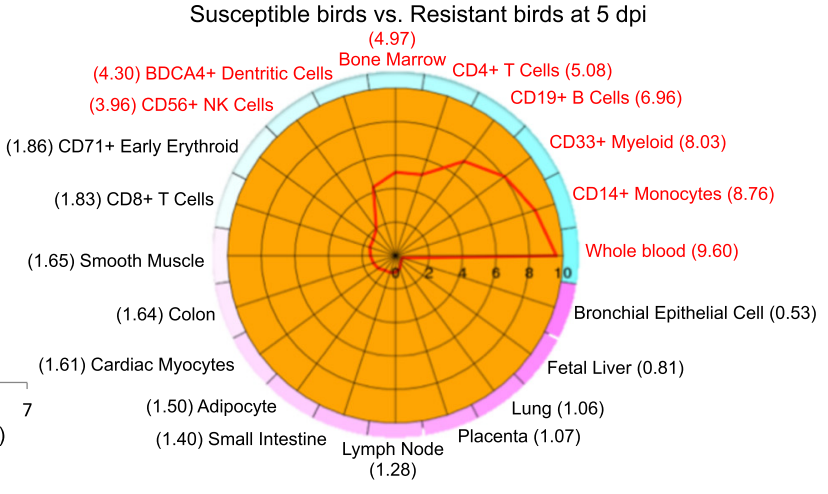

Susceptible birds vs. Non-challenged birds at 5 dip

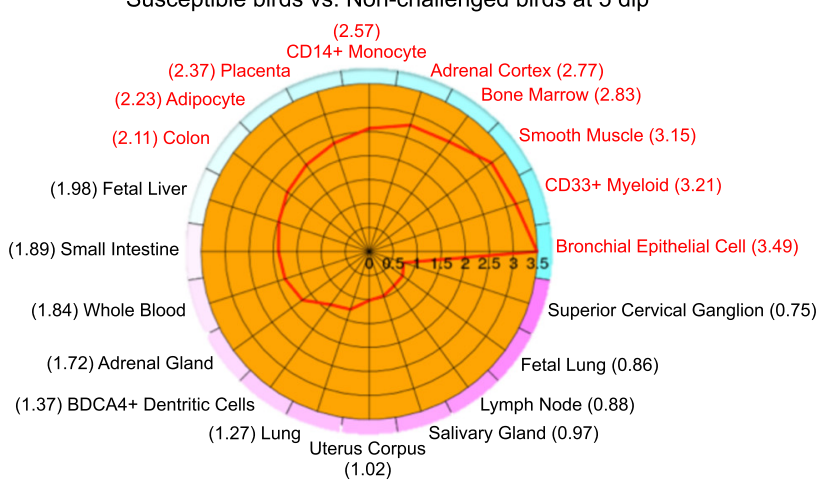

5 dpi vs. $1 \mathrm{dpi}$ in susceptible birds

$$
\text { (6.18) }
$$

(4.55) CD4+ T Cells Lymph Node BDCA4+ Dentritic Cells (10.73)

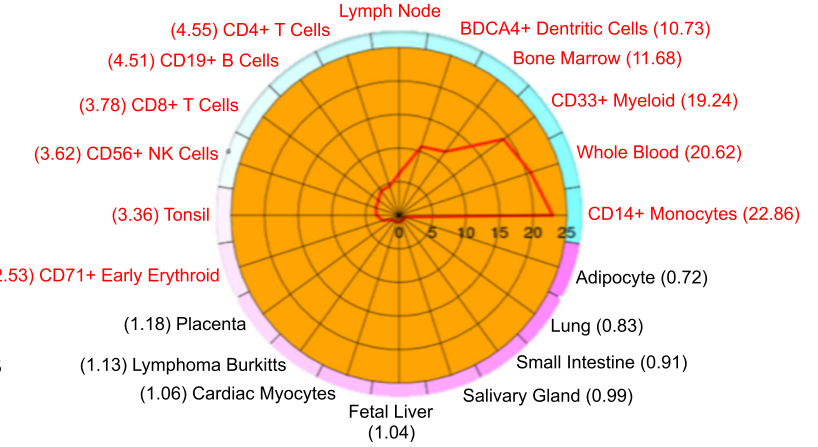

Fig. 5 (See legend on next page.) 
(See figure on previous page.)

Fig. $5 \mathrm{GO}$ terms and CTen analysis. The list of differentially expressed (DE) genes in bone marrow from broilers infected with APEC is analyzed by GOseq and CTen. The left shows the functional annotation for DE genes in the four contrasts: top ten significant GO biological processes. The right shows the summary of cell type enrichment analysis expressed as - $\log 10$ (Benjamini and Hochberg adjusted P value). The characters in red color indicate significantly enriched cell type. The color from blue to pink indicates the enrichment from the highest to lowest, respectively. GO, gene ontology; CTen, cell type enrichment; dpi, day post-infection

T cells, CD19+ B cells, and CD56+ NK cells. These results suggest that APEC induces the activation of many immune cells in challenged-susceptible birds by 5 dpi. However, in the contrast of challenged-susceptible vs. nonchallenged birds at $1 \mathrm{dpi}$, the cell type enrichment did not show many immune cells, only CD33+ myeloid, bone marrow, and CD14+ monocyte (Fig. 5). This difference over time may indicate an impairment of precursor immune cells in challenged-susceptible birds early after APEC infection.

GOseq was used to interpret DE genes into a meaningful biological context. Using the default settings, GOseq identified many significant GO terms. Figure 5 presents the top 10 significant GO terms in the four contrasts. For the three contrasts: susceptible vs. nonchallenged birds at $5 \mathrm{dpi}$, susceptible vs. resistant birds at $5 \mathrm{dpi}$, and $5 \mathrm{dpi}$ vs. $1 \mathrm{dpi}$ in susceptible birds, the significant GO terms that were enriched included defense response, leukocyte activation and differentiation, lymphocyte activation, and immune response, which is in strong concordance with the CTen results. However, in the contrast of susceptible vs. non-challenged birds at 1 dpi, the significant GO terms focused on apoptosis, cell death, and immune response.

\section{Heatmap pathway analysis}

Many canonical pathways were identified as significant in the nine contrasts with FDR controlled at 0.05. Figure 6 shows a heatmap comparison of pathways in the nine contrasts. We detected nine significant pathways that were related to immune system, signal transduction, signaling molecules and interaction, and transport and catabolism. All nine pathways were strongly and significantly induced at $5 \mathrm{dpi}$ in susceptible vs. non-challenged birds and in susceptible vs. resistant birds (Fig. 6). Most of the nine pathways had significant induction states in the same two contrasts on 1 dpi (Fig. 6). Only the T cell receptor signaling pathway, phagosome pathway, and cytokine-cytokine receptor interaction pathway had significant suppression in the contrasts of susceptible vs. non-challenged birds or susceptible vs. resistant birds on 1 dpi (Fig. 6). However, these three pathways appeared to reverse to a more inductive state in the same contrasts on $5 \mathrm{dpi}$. Interestingly, there were no significant pathways associated with the contrasts of 5 dpi vs. 1 dpi in either resistant birds or in nonchallenged birds. However, several immune related pathways, phagosome pathway, lysosome pathway, and cytokine-cytokine receptor interaction pathway were significantly induced in susceptible birds over post-infection

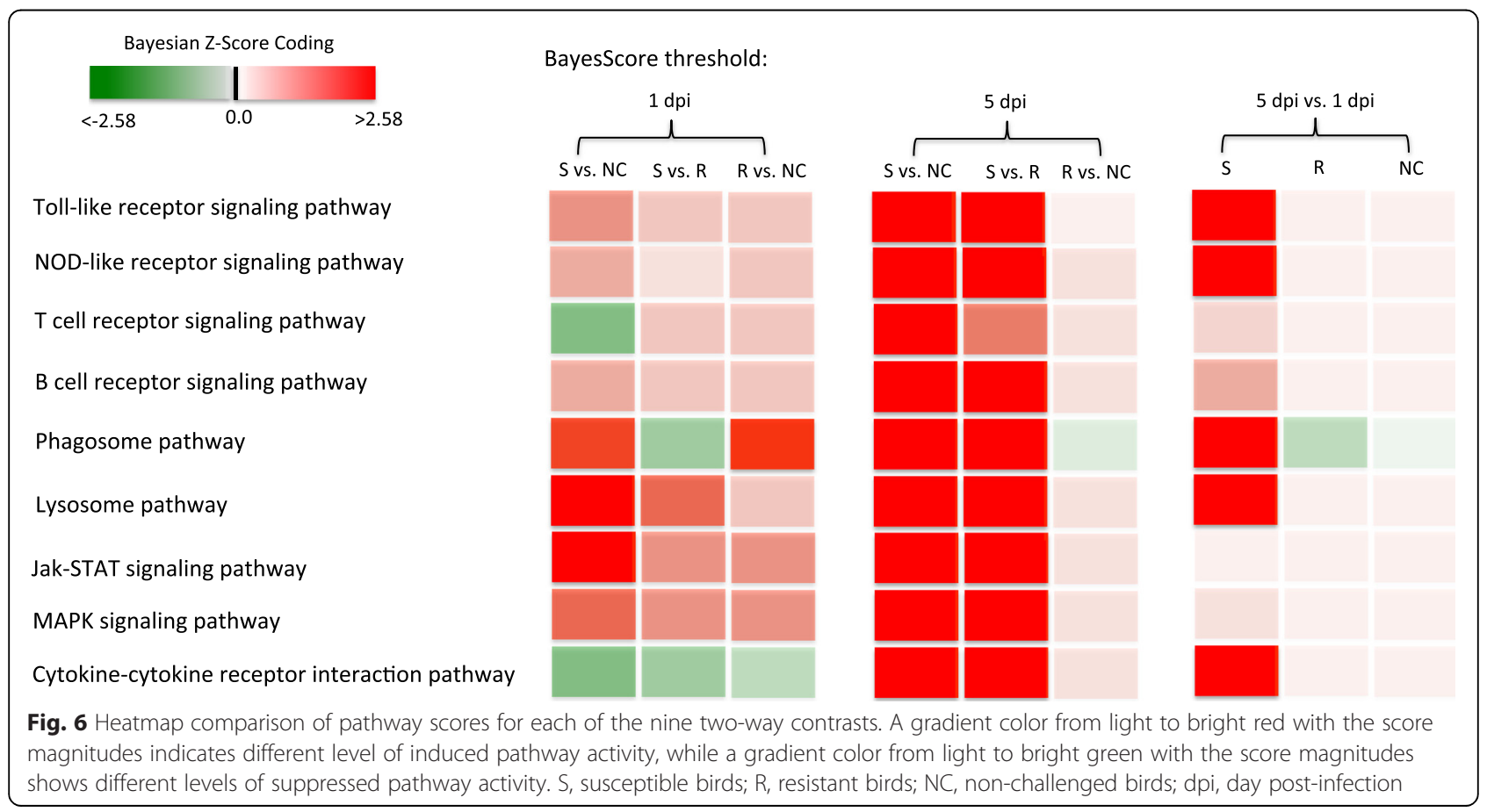


time (Fig. 6). These results indicate that, in susceptible birds infected with APEC, the host defenses are increasingly induced over time. Moreover, APEC-infected susceptible birds express unique biosignatures compared to resistant birds.

\section{Quantitative PCR validation for RNAseq results}

Quantitative PCR (qPCR) was utilized to validate results of fifteen significant immune-related genes from the RNAseq study (FDR < 0.05): ADA, BLNK, CD3D, CD28, CD40, CD3Z, IFNG, IL1, IL7, IL8, IL18, LIG4, MD2,
NOD1, and TLR4. Moreover, all the validated DE genes that we selected had high expression (Additional file 1: Table S2). The qPCR validation was carried out on five contrasts that had the largest numbers of $\mathrm{DE}$ genes in RNAseq: susceptible vs. non-challenged birds at $5 \mathrm{dpi}$, susceptible vs. resistant birds at $5 \mathrm{dpi}, 5 \mathrm{dpi}$ vs. $1 \mathrm{dpi}$ in susceptible birds, susceptible vs. non-challenged birds at $1 \mathrm{dpi}$, and susceptible vs. resistant birds at $1 \mathrm{dpi}$. Results from qPCR are generally similar to those of RNAseq in both the direction of fold change and significance (Table 2).

Table 2 Quantitative PCR validation

\begin{tabular}{|c|c|c|c|}
\hline Gene & Contrast & qPCR & RNA-seq \\
\hline \multirow[t]{3}{*}{ ADA } & Susceptible vs. Non-challenged birds at 5 dpi & $-15.66^{* *}$ & $-3.92^{* *}$ \\
\hline & Susceptible vs. Resistant birds at 5 dpi & $-18.99^{* *}$ & $-3.39 * *$ \\
\hline & 5 dpi vs. $1 \mathrm{dpi}$ in susceptible birds & $-9.29^{* *}$ & $-2.50^{* *}$ \\
\hline \multirow[t]{3}{*}{ BLNK } & Susceptible vs. Non-challenged birds at $5 \mathrm{dpi}$ & $+3.11^{*}$ & $+2.50^{* *}$ \\
\hline & Susceptible vs. Resistant birds at 5 dpi & $+4.71^{* *}$ & $+2.22^{*}$ \\
\hline & 5 dpi vs. 1 dpi in susceptible birds & $+3.85^{* *}$ & $+2.19^{* *}$ \\
\hline CD3D & Susceptible vs. Non-challenged birds at $1 \mathrm{dpi}$ & $-2.36^{* *}$ & $-1.67^{* *}$ \\
\hline CD28 & Susceptible vs. Non-challenged birds at $5 \mathrm{dpi}$ & $+7.17^{* *}$ & $+2.27^{*}$ \\
\hline \multirow[t]{3}{*}{ CD40 } & Susceptible vs. Non-challenged birds at 5 dpi & $+4.40^{* *}$ & $+2.93^{* *}$ \\
\hline & Susceptible vs. Resistant birds at 5 dpi & $+2.44^{* *}$ & $+2.25^{* *}$ \\
\hline & 5 dpi vs. 1 dpi in susceptible birds & $+2.25^{*}$ & $+1.91^{* *}$ \\
\hline \multirow[t]{2}{*}{ CD3Z } & Susceptible vs. Non-challenged birds at $1 \mathrm{dpi}$ & -1.91 & $-1.77^{* *}$ \\
\hline & Susceptible vs. Resistant birds at 5 dpi & $-7.05^{*}$ & $-2.11^{* *}$ \\
\hline IFNG & Susceptible vs. Non-challenged birds at $1 \mathrm{dpi}$ & $-2.19^{* *}$ & $-1.71^{*}$ \\
\hline IL1 & Susceptible vs. Non-challenged birds at 5 dpi & $+2.41^{*}$ & $+5.21^{* *}$ \\
\hline \multirow[t]{3}{*}{ IL7 } & Susceptible vs. Non-challenged birds at 5 dpi & $-3.38^{* *}$ & $-4.69^{* *}$ \\
\hline & Susceptible birds vs. Resistant birds at 5 dpi & $-1.96^{*}$ & $-3.36^{*}$ \\
\hline & 5 dpi vs. 1 dpi in susceptible birds & $+2.72^{*}$ & $+5.43^{* *}$ \\
\hline \multirow[t]{3}{*}{ IL8 } & Susceptible vs. Non-challenged birds at 5 dpi & $+6.70^{* *}$ & $+6.06^{* *}$ \\
\hline & Susceptible vs. Resistant birds at $5 \mathrm{dpi}$ & $+2.69^{*}$ & $+2.72^{* *}$ \\
\hline & 5 dpi vs. 1 dpi in susceptible birds & $+3.89^{*}$ & $+2.37^{*}$ \\
\hline \multirow[t]{2}{*}{ IL18 } & Susceptible vs. Non-challenged birds at $5 \mathrm{dpi}$ & $+6.47^{* *}$ & $+3.97^{* *}$ \\
\hline & Susceptible vs. Resistant birds at $5 \mathrm{dpi}$ & $+2.40^{*}$ & $+2.82^{* *}$ \\
\hline LIG4 & Susceptible vs. Non-challenged birds at 5 dpi & $-6.14^{* *}$ & $-1.57^{*}$ \\
\hline \multirow[t]{3}{*}{ MD2 } & Susceptible vs. Non-challenged birds at 5 dpi & $+2.39^{* *}$ & $+3.10^{* *}$ \\
\hline & Susceptible vs. Resistant birds at $5 \mathrm{dpi}$ & $+2.26^{* *}$ & $+2.55^{* *}$ \\
\hline & 5 dpi vs. 1 dpi in susceptible birds & $+2.16^{* *}$ & $+1.83^{* *}$ \\
\hline \multirow[t]{2}{*}{ NOD1 } & Susceptible vs. Non-challenged birds at 5 dpi & $+2.77^{*}$ & $+2.17^{* *}$ \\
\hline & Susceptible vs. Resistant birds at 5 dpi & $+5.36^{* *}$ & $+1.97^{* *}$ \\
\hline \multirow[t]{3}{*}{ TLR4 } & Susceptible vs. Non-challenged birds at $5 \mathrm{dpi}$ & $+3.26^{* *}$ & $+2.77^{* *}$ \\
\hline & Susceptible vs. Resistant birds at 5 dpi & $+2.53^{*}$ & $+2.35^{* *}$ \\
\hline & 5 dpi vs. 1 dpi in susceptible birds & $+2.75^{*}$ & $+1.89^{* *}$ \\
\hline
\end{tabular}

Note: Fold change between contrasts presented in third and fourth column. + values indicate higher expression in the first group, - values indicate higher expression in the second group. ** is $P$ value $<0.01$ in qPCR or FDR $<0.01$ in RNA-seq; ${ }^{*}$ is $P$ value $<0.05$ in qPCR or FDR $<0.05$ in RNA-seq. 


\section{Discussion}

This study used a novel experimental design to enable the study of challenged birds with two extreme pathology levels: severe lesions (susceptible) and mild lesions (resistant), with the aim to elucidate resistance and susceptibility mechanisms. This design, therefore, is more comprehensive than previous experiments with other avian pathogens that only assessed the contrast of non-challenged with challenged birds [27, 28]. Figure 2 illustrates the wide distribution of lesion score (0-7) phenotypes in the challenged group. The PCA results (Fig. 3) further validate the concept that the bone marrow transcriptome response of APEC-challenged birds that are susceptible (severe lesion) is very distinct from those that are resistant (mild lesion). Large numbers of DE genes were detected in the four contrasts: susceptible vs. non-challenged at $5 \mathrm{dpi}$, susceptible vs. resistant at $5 \mathrm{dpi}, 5 \mathrm{vs.} 1 \mathrm{dpi}$ in susceptible birds, and susceptible vs. non-challenged at $1 \mathrm{dpi}$. To determine the populations of specific particular cell types that responded to the differences in transcriptional activity, the CTen database information was used to detect the cell types for these four contrasts. The CTen database likely misses the identification of some cell types in the current study, because it is based on mammalian (mouse and human) tissues and cell types. However, because $60 \%$ of chicken genes correspond to a similar human gene [29], the mammalian data in the CTen can serve as an initial reference to identify specific cell types that respond to APEC infection in birds. Large numbers of DE genes were enriched in immune related cells, which corresponds to monocytes, DCs, CD4+/CD8+ T cells, B cells, and NK cells migration to the site of APEC infection. The cell type enrichment, GO term, and pathways analysis are all consistent, thus confirming the results of each individual analysis.

DCs, which are efficient antigen presenting cells (APCs), play a vital role in both innate and adaptive immune response. Based on CTen results, 267 (75.28 \% upregulated), 173 (66.47 \% up-regulated), and 167 (82.63\% up-regulated) significant DE genes were detected in DCs in the contrasts of susceptible vs. non-challenged birds at $5 \mathrm{dpi}$, susceptible vs. resistant birds at $5 \mathrm{dpi}$, and susceptible birds at 5 dpi vs. $1 \mathrm{dpi}$, respectively. Environmental stimuli and pathogens can have a major effect on the functions and maturation of DCs [30-32]. Mature DCs that are promoted by toll like receptor (TLR) ligand binding have the ability to drive naive $\mathrm{T}$ cells to become effector $\mathrm{T}$ cells (T helper 1 and 2) [33, 34].

Monocytes were significantly changed in current study, with 269 (81.78 \% up-regulated), 169 (75.15\% upregulated), and 177 (90.40\% up-regulated) significant $\mathrm{DE}$ genes in susceptible vs. non-challenged birds at 5 dpi, susceptible vs. resistant birds at $5 \mathrm{dpi}$, and susceptible birds at $5 \mathrm{dpi}$ vs. $1 \mathrm{dpi}$, respectively. Monocytes can differentiate into DCs and macrophages [35-37].
Macrophages have a relative long life-span before they remove the pathogens invasion. The functions of macrophages include phagocytosis of foreign particles, secretion of enzymes and oxidative metabolites, cytokine production, APC, and opsonization [38-40]. Macrophages can produce a variety of cytokines involved in the pro-inflammatory response like IL1, IL6, and TNFo [41, 42]. Also, macrophages have an important role as APC in activating the immune response of $\mathrm{T}$ cells.

NK cells, a third lymphoid lineage and thymusindependent, have many similar characteristics with cytotoxic $\mathrm{T}$ cells; they both respond against a wide variety of pathogens by production of a serine protease and a pore-forming protein $[43,44]$. In the current study, 246 (74.39 \% up-regulated), 157 (63.69 \% up-regulated), and 133 (82.71\% up-regulated) DE genes were involved in NK cells in the contrasts of susceptible vs. nonchallenged birds at $5 \mathrm{dpi}$, of susceptible vs. resistant birds at $5 \mathrm{dpi}$, and of $5 \mathrm{dpi}$ vs. $1 \mathrm{dpi}$ in susceptible birds, respectively. The NK cells play a key role in host primary defense and the homeostasis of normal tissues as part of the innate immune system [45]. Taking the results on bone marrow NK cells, macrophages and DCs collectively, there is significant activation of the myeloid cells of the innate immune system occurring soon after APEC infection.

In addition to the immune cells, many innate immune response signaling pathways, including TLR- and NODlike receptors, were significantly changed. Based on chicken KEGG pathways (gga04620 and gga04621) and the bone marrow transcriptome data from this APECchallenge study, we modelled the detailed interaction of genes in the bone marrow transcriptome in the toll-like receptor and NOD-like receptor signaling pathways (Fig. 7Aa and $\mathrm{Ab}$ ).

TLRs respond to bacterial peptidoglycan (PGN) components in the extracellular environment by triggering production of pro-IL1 $\beta$ and pro-IL18, resulting in intracellular inflammasome activation and leading to NALP3 > ASC > CASP1 > pyroptosis or inflammatory response associated with phagosome and lysosome pathways (Fig. 7Aa, Ab). In the current study, in the important TLR signaling pathway (TLR1/2/4/5/7 > IRAK $>$ TRAF6 $>$ TAB1 $/ 2>$ IKK $>$ Tpl $2>$ MEK $1 / 2>$ ERK $>$ AP1 $>$ pro-IL1 $\beta$ and IL1 $8>$ NALP3 $>$ ASC $>$ CASP1 $>$ IL1 $\beta$ and IL18 cytokines), all genes except for TRAF6 were upregulated in susceptible vs. non-challenged birds at $5 \mathrm{dpi}$ (Fig. 7Aa). These results indicate that the innate immune response is highly activated in susceptible birds. Similar to the susceptible vs. non-challenged contrast at $5 \mathrm{dpi}$, the contrasts of susceptible birds at $5 \mathrm{vs.} 1 \mathrm{dpi}$ and of susceptible vs. resistant birds at $5 \mathrm{dpi}$ also had higher expression of many of the same genes (Fig. 7Aa). Other signaling 


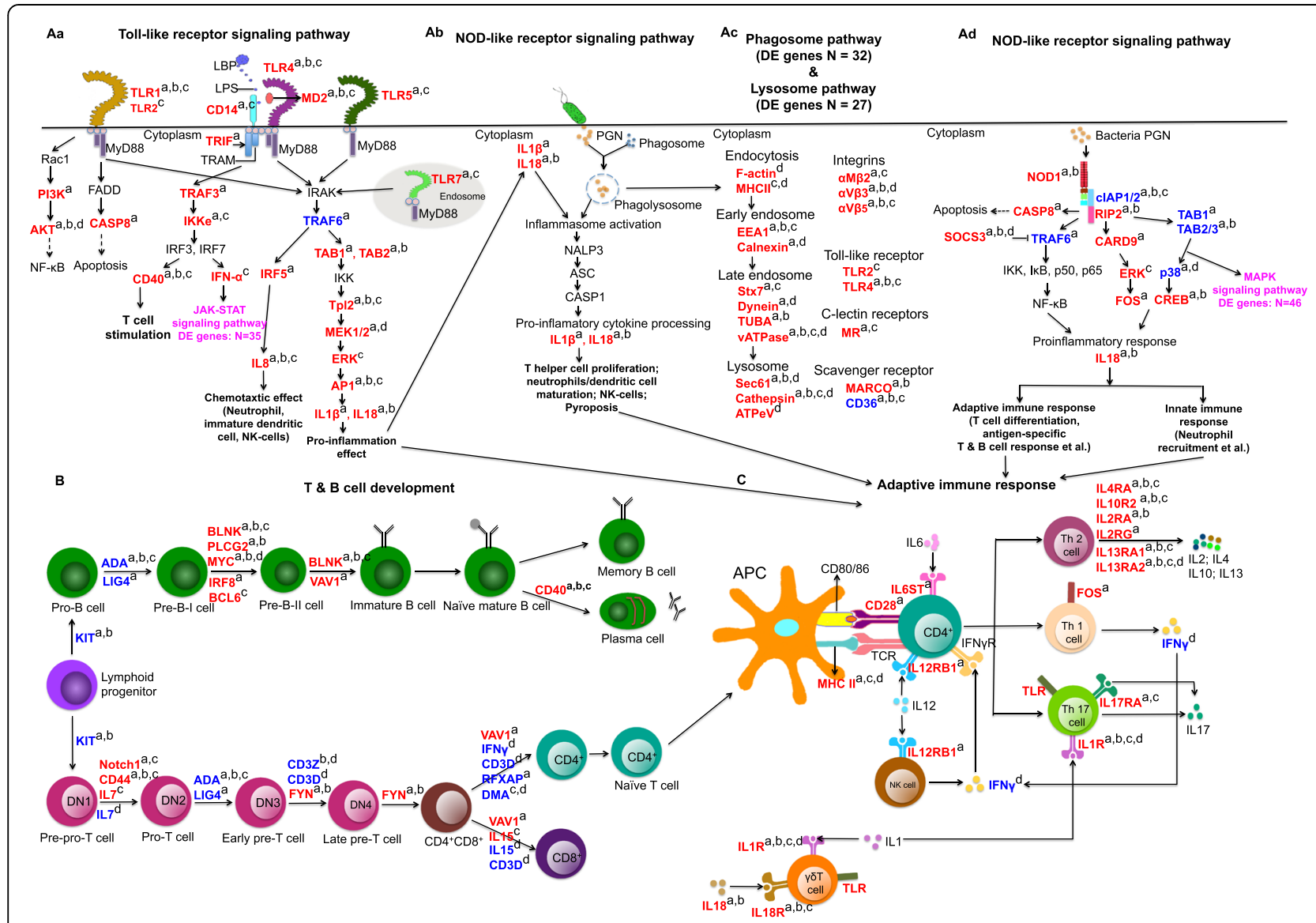

Fig. 7 Dynamic differentially expressed (DE) genes were involved in T and B cell development as well as innate and adaptive immune response. $A a, A b$, and $A c$ were innate immune response including toll-like receptor signaling pathway, NOD-like receptor signaling pathway, phagosome and lysosome pathway. B indicates the process of B and $T$ lymphocytes lymphopoiesis and the regulation genes in each step. C represents adaptive immune response under APEC infection. Genes in blue color were down-regulated while genes in red color were up-regulated. The pink color indicates significantly changed pathways that were not discussed here. The lowercase a, b, c, d indicate different contrasts: a, day 5 susceptible birds vs. day 5 non-challenged birds; b, day 5 susceptible birds vs. day 5 resistant birds; c, day 5 susceptible birds vs. day 1 susceptible birds; d: day 1 susceptible birds vs. day 1 non-challenged birds. LBP, lipopolysaccharide binding protein; LPS, lipopolysaccharide; PGN, peptidoglycan; N, number

pathways were also detected, including TLR1/2 $>$ FADD $>$ CASP8 $>$ apoptosis and TLR4 $>$ TRIF $>$ TRAF3 $>$ IKKe $>$ IRF3/7 $>$ IFN $\alpha>$ JAK-STAT signaling pathway. The DE genes in the above pathways were up-regulated in susceptible vs. non-challenged birds at $5 \mathrm{dpi}$, and at 5 vs. 1 dpi in susceptible birds (Fig. 7Aa). In summary, most genes in this model exhibit increased expression in challenged-susceptible birds compared to challengedresistant or non-challenged birds at $5 \mathrm{dpi}$, indicating that susceptible birds have enhanced activation of their innate immune response after APEC infection.

When bacterial PGN components enter into host cells, phagosomes produced by neutrophils or macrophages are activated and the pathway of NOD $1>\operatorname{cIAP} 1 / 2>$ RIP2 $>$ TAB1/2/3 > ERK/p38 (MAPK signaling pathway) > pro-inflammatory cytokine (IL8) is initiated. Based on our current study's data and the chicken KEGG database (gga04621), we propose the model in Fig. 7Ab. All the genes of the
NOD1 pathway were significantly DE in susceptible vs. non-challenged birds at $5 \mathrm{dpi}$ in the current study. The initial function of cIAP1/2 is to inhibit cell death [46]. TRAF6 is inhibited by SOCS3 [47], which blocks NF-kB signaling and plays a vital role in the TLR signaling pathway [48]. RIP2 also plays a crucial role in TCR signaling, $\mathrm{T}$ cell differentiation, and TLR2/3/4 recruitment $[49,50]$. In the current study, SOCS3, NOD1, RIP2, CARD9, ERK, FOS, and IL18 were up-regulated, whereas TRAF6 and CIAP1/2 were down-regulated in susceptible vs. non-challenged birds at 5 dpi (Fig. 7Ab). These data indicate that the RIP2 pathway is enhanced whereas the TRAF6 pathway is impaired in bone marrow cells of APEC-infected birds. Collectively, the defense responses of challenged-susceptible birds at $5 \mathrm{dpi}$ are characterized by the induction of multiple innate immune signaling pathways.

Development of $\mathrm{T}$ and $\mathrm{B}$ cells was also significantly changed during APEC infection. Based on $\mathrm{T}$ and $\mathrm{B}$ cell 
development models in mammals and data of the current study, we propose the important genes and cytokines that influence $\mathrm{T}$ and $\mathrm{B}$ cell status under APEC infection (Fig. 7B). The crucial genes include KIT, Notch1, CD44, IL7, LIG4, ADA, CD3, FYN, and VAV1 [51-58]. Genes Notch1, CD44, FYN, and VAV were up-regulated in susceptible vs. non-challenged birds at $5 \mathrm{dpi}$, indicating the general trend of increase of expression of key genes in susceptible birds during APEC infection. Similar phenomena were also observed in susceptible vs. resistant birds at $5 \mathrm{dpi}$ and also in $5 \mathrm{dpi}$ vs. 1 dpi in susceptible birds. However, most of the above genes were down-regulated in susceptible vs. non-challenged birds at $1 \mathrm{dpi}$, suggesting $\mathrm{T}$ cell development was largely impaired at the initial APEC infection time in susceptible birds. In summary, the development of T lymphocytes, TCR signaling were impaired in challenged-susceptible birds at $1 \mathrm{dpi}$, but were enhanced by 5 dpi.

For pre-BCR and BCR signaling in mammals, BLNK, PLCG2, MYC, VAV1, CD40, and BCL6 play a central role in many B-cell transitions [59-63]. Also, BLNK has been reported to be important to $\mathrm{BCR}$ signal transduction in chickens [64]. In the current study, all those genes were up-regulated in susceptible vs. non-challenged birds at 5 dpi and also in susceptible vs. resistant birds at 5 dpi. Moreover, IRF8 is a critical transcriptional regulator of B cell lineage specification, commitment, and differentiation in mice [65]. IRF8 was only up-regulated in susceptible vs. non-challenged birds at $5 \mathrm{dpi}$. Collectively, our data indicate that pre-BCR and BCR signaling are greatly enhanced at $5 \mathrm{dpi}$ in challenged-susceptible birds, compared to nonchallenged and challenged-resistant birds.

The adaptive immune response was also activated by cytokines and chemokines produced from the innate immune response (Fig. 7C). APCs, especially DCs, interact with naive T cells through CD80/86, CD28, MHC II, and TCR to produce effector T cells [66, 67]. In the current study, CD28 was more highly expressed in susceptible vs. non-challenged birds at 5 dpi. MHC II (BLB1 and DMA) was more highly expressed in susceptible birds at $5 \mathrm{dpi}$ than $1 \mathrm{dpi}$, while it was expressed less in susceptible than non-challenged birds at $1 \mathrm{dpi}$. These data suggest that host adaptive immunity is impaired immediately post-infection, but becomes actively enhanced over time to resist infection. The cytokines, IL1, IL18, IL6, IL12, and IL17, can interact with T cells to resist infection in humans and mice $[68,69]$. In the current study, those cytokines or their receptors were expressed more highly in susceptible vs. non-challenged birds at 5 dpi (Fig. 7C). Moreover, IL1R, IL18R, and IL17R were also more highly expressed in susceptible birds at 5 dpi than at $1 \mathrm{dpi}$. In humans and mice, T helper 2 (Th2) cells produce cytokines IL2, IL4, IL10, and IL13 to induce antibody production [70,71]. Although these cytokines did not change in gene expression in bone marrow in the current study, their receptors' genes had increased expression in susceptible vs. non-challenged birds at $5 \mathrm{dpi}$, in susceptible vs. resistant birds at $5 \mathrm{dpi}$, and in susceptible birds at $5 \mathrm{dpi}$ vs. $1 \mathrm{dpi}$ (Fig. $7 \mathrm{C}$ ). In summary, the higher expression of cytokines and their receptors in susceptible birds at 5 dpi indicates that APEC infection results in the extensive activation of adaptive immune response in bone marrow cells over post-challenge time.

Moreover, as we expected, the apoptosis and other cell death mechanisms were also detected in challengedsusceptible birds compared to non-challenged birds in both $1 \mathrm{dpi}$ and $5 \mathrm{dpi}$. Apoptosis, a major cell death procession, plays an essential role in organism growth and tissue homeostasis [72, 73]. Normally, apoptosis is accompanyed with inflammation and inflammasome to remove the dead cells or abnormal cells [74]. As the susceptible birds had severe lesions, it was reasonable to observe strong apoptosis and cell death in susceptible birds. At $1 \mathrm{dpi}$, five DE genes were significantly upregulated in challenged-susceptible birds in apoptosis pathway compared to non-challenged birds: PIK3CD, CYCS, AKT1, IL1RAP, and PIK3R1. Over time postinfection, apoptosis was enhanced in challengedsusceptible birds. Except the above five DE genes, seven DE genes involved in apoptosis pathway were upregulated in challenged-susceptible birds compared to non-challenged birds at 5 dpi: CASP6, CAPN1, IL1R1, TNFRSF1A, IL1 $\beta$, CASP8, and TRADD.

All the above discussions were focused on the four contrasts with large numbers of DE genes: susceptible vs. non-challenged birds at $5 \mathrm{dpi}$, susceptible vs. resistant birds at $5 \mathrm{dpi}, 5 \mathrm{dpi}$ vs. $1 \mathrm{dpi}$ in susceptible birds, and susceptible vs. non-challenged birds at $1 \mathrm{dpi}$. Although we detected small numbers of DE genes in challengedresistant birds compared to non-challenged birds $(\mathrm{N}=$ 189 at $1 \mathrm{dpi}$ and $\mathrm{N}=2$ at $5 \mathrm{dpi}$ ), many significantly changed pathways were also identified at $1 \mathrm{dpi}$ : phagosome, Jak-STAT signaling pathway, and MAPK signaling pathway (Fig. 6). Only CD33+ myeloid cells were detected in resistant vs. non-challenged birds at $1 \mathrm{dpi}$, indicating innate immune response is the major mechanism for challenged-resistant birds to respond to APEC infection. Compared to challenged-susceptible birds, day 1 challenged-resistant birds only had fifty DE genes (40 up- and 10 down-regulated). However, of those 40 DE genes, 9 were novel genes; 3 genes' proteins were not characterized; and the other $28 \mathrm{DE}$ genes were highly related to immune function: CD74 molecule (li); cathepsin Z (CTSZ); Ras family (RIN2 and RASGEF1B); immunoglobulin (IGJ); interleukin (IL7 and IL18R1); tumor necrosis factor (TNFRSF21); transforming growth factor (TGFBI); and erythrocyte membrane protein (EPB41L3). Challenged-resistant birds, therefore, 
enhanced many immune genes expression to resist the early APEC infection.

\section{Conclusion}

This is the first report, to our knowledge, examining the role of bone marrow cell gene expression in response to APEC infection in chickens. This transcriptome study provides insight and a genome-level view into the response of cell types and genes involved in the earliest phases of the immune response to APEC infection. Our data indicate a dynamic interaction between the innate and adaptive immune responses to APEC infection in susceptible birds, providing flexibility and redundancy in the host's induction of cytokines and chemokines. Additionally, $\mathrm{B}$ cell and $\mathrm{T}$ cell development are also extensively affected by APEC infection in challengedsusceptible birds, resulting in drastic host impairment in early response to infection. This impairment of the early response may cause the delayed initiation of the cytokine response, resulting in the greater level of pathology (susceptibility to disease) in these birds. The DE genes related to immune response interaction exert their function in a highly coordinated fashion where multiple pathways are involved in $\mathrm{T}$ and $\mathrm{B}$ cell development, differentiation, proliferation and maturation in bone marrow. As post-infection time progressed, bone marrow cells of challenged-susceptible birds actively triggered different facets of the immune response. The transcriptomic profile of challenged-resistant birds suggests an immune system that differs only slightly from that of non-challenged birds, perhaps because the challengedresistant phenotype has little need to activate the immune system at a high level to control APEC-induced disease. In contrast, in the challenged-susceptible birds, the DE genes in the immune cells and the identified signaling models are representative of activation and resolution of infection at both assayed post-infection days. The present study sheds light on the genomic modulation of the immune response against APEC infection in chickens. By contrasting the response of challenged-resistant vs. challenged-susceptible phenotypes, in addition to challenged vs. non-challenged birds, this study also builds a foundation for identifying host genetic variation that may be manipulated to enhance resistance to infection and colibacillosis.

\section{Additional file}

Additional file 1: Table S1. Primers sequence for $\mathrm{QPCR}$ validation.

Table S2. Quantitative PCR validation. (XLSX 44 kb)

\section{Competing interests}

The authors declare that there were no competing interests regarding the publication of this paper.

\section{Authors' contributions}

HS isolated RNA from tissues and generated cDNA libraries, analyzed data of the RNAseq experiment, conducted GPCR validation, and wrote the manuscript. PL, LKN, and SJL conceived the concept, participated in the animal experiments, and revised the manuscript. All authors read and approved the final manuscript.

\section{Acknowledgements}

The authors gratefully acknowledge the assistance of members of the Nolan and Lamont labs in collecting tissues for this study, Michael Kaiser for technical assistance in $\mathrm{QPCR}$, and grant support.

This work was supported by The United States Department of Agriculture National Institute of Food and Agriculture, Hatch Project number 5203 and Grant no. 2008-35604-18805 from the USDA National Institute of Food and Agriculture Microbial Genome Program.

\section{Author details}

'Department of Animal Science, lowa State University, Ames, lowa 50011, USA. ${ }^{2}$ Department of Statistics, lowa State University, Ames, lowa 50011, USA. ${ }^{3}$ Department of Veterinary Microbiology and Preventive Medicine, lowa State University, Ames, lowa 50011, USA.

Received: 26 May 2015 Accepted: 17 August 2015

Published online: 15 September 2015

\section{References}

1. Antao EM, Glodde S, Li G, Sharifi R, Homeier T, Laturnus C, et al. The chicken as a natural model for extraintestinal infections caused by avian pathogenic Escherichia coli (APEC). Microb Pathog. 2008;45(5-6):361-9.

2. Kemmett K, Humphrey T, Rushton S, Close A, Wigley P, Williams NJ. A Longitudinal Study Simultaneously Exploring the Carriage of APEC Virulence Associated Genes and the Molecular Epidemiology of Faecal and Systemic E. coli in Commercial Broiler Chickens. Plos One. 2013;8(6):e67749. doi:10.1371/journal.pone.0067749.

3. JanBen T, Schwarz C, Preikschat P, Voss M, Philipp HC, Wieler LH. Virulenceassociated genes in avian pathogenic Escherichia coli (APEC) isolated from internal organs of poultry having died from colibacillosis. Int Med Microbiol. 2001;291:371-8.

4. Stordeur P, Bree A, Mainil J, Moulin-Schouleur M. Pathogenicity of papnegative avian Escherichia coli isolated from septicaemic lesions. Microb Infect. 2004;6(7):637-45.

5. Manges AR, Johnson JR. Food-borne origins of Escherichia coli causing extraintestinal infections. Clin Infect Dis. 2012;55(5):712-9. doi:10.1093/cid/cis502.

6. Vincent C, Boerlin P, Daignault D, Dozois CM, Dutil L, Gala-nakis C, et al. Food reservoir for Escherichia coli causing urinary tract infections. Emerg Infect Dis. 2010;16(1):88-95. doi:10.3201/eid1601.091118.

7. Bergeron CR, Prussing C, Boerlin P, Daignault D, Dutil L, Reid-Smith RJ, et al. Chicken as reservoir for extraintestinal pathogenic Escherichia coli in humans. Canada. Emerg Infect Dis. 2012;18(3):415-21. doi:10.3201/eid1803.111099.

8. Ewers C, Li G, Wilking H, Kiebetaling S, Alt K, Antao EM, et al. Avian pathogenic, uropathogenic, and newborn meningitis-causing Escherichia coli: How closely related are they? Int J Med Microbiol. 2007;297(3):163-76.

9. Johnson TJ, Kariyawasam S, Wannemuehler Y, Mangiamele P, Johnson SJ, Doetkott C, et al. Genome sequence of avian pathogenic Escherichia coli strain $01: K 1: H 7$ shares strong similarities with human extraintestinal pathogenic Escherichia coli (ExPEC) genomes. J Bacteriol. 2007;189(8):3228-36.

10. Kariyawasam S, Wilkie BN, Gyles CL. Construction, characterization, and evaluation of the vaccine potential of three genetically defined mutants of avian pathogenic Escherichia coli. Avian Dis. 2004;48(2):287-99.

11. Salehi TZ, Tabatabaei S, Karimi V, Fasaei BN, Derakhshandeh A, Jahromi AO Assessment of immunity against avian colibacillosis induced by an aro $\mathrm{A}$ mutant containing increased serum survival gene in broilers. Braz J Microbiol. 2012;43(1):363-70. doi:10.1590/S1517-838220120001000043.

12. Murphy K. Janeway's Immunobiology. 8th ed. Garland Science: Taylor \& Francis Group, LLC:; 2012.

13. Kondo M, Weissman IL, Akashi K. Identification of clonogenic common lymphoid progenitors in mouse bone marrow. Cell. 1997:91(5):661-72.

14. Gabrilovich DI, Ostrand-Rosenberg S, Bronte V. Coordinated regulation of myeloid cells by tumors. Nat Rev Immunol. 2012;12(4):253-68. doi:10.1038/nri3175. 
15. Ciraci C, Tuggle CK, Wannemuehler MJ, Nettleton D, Lamont SJ. Unique genome-wide transcriptome profiles of chicken macrophages exposed to Salmonella-derived endotoxin. BMC Genomic. 2010;11:545-56. doi:10.1186/1471-2164-11-545.

16. Ross DT, Scherf U, Eisen MB, Perou CM, Rees C, Spellman P, et al. Systematic variation in gene expression patterns in human cancer cell lines. Nat Genet. 2000;24(3):227-35.

17. Alizadeh AA, Eisen MB, Davis RE, Ma C, Lossos IS, Rosenwald A, et al. Distinct types of diffuse large B-cell lymphoma identified by gene expression profiling. Nature. 2000:403(6769):503-11.

18. Bahar R, Hartmann CH, Rodriguez KA, Denny AD, Busuttil RA, Dolle MET, et al. Increased cell-to-cell variation in gene expression in ageing mouse heart. Nature. 2006:441(7096):1011-4.

19. Peighambari SM, Julian RJ, Gyles CL. Experimental Escherichia coli respiratory infection in broilers. Avian Dis. 2000;44(4):759-69.

20. Sandford EE, Orr M, Shelby M, Li XY, Zhou HJ, Johnson TJ, et al. Leukocyte transcriptome from chickens infected with avian pathogenic Escherichia coli identifies pathways associated with resistance. Results Immunol. 2012;2:44-53. doi:10.1016/j.rinim.2012.02.003.

21. Sandford EE, Orr M, Balfanz EN, Bowerman N, Li X, Zhou H, et al. Spleen transcriptome response to infection with avian pathogenic Escherichia coli in broiler chickens. BMC Genomics. 2011;12:469. doi:10.1186/1471-2164-12-469.

22. Robinson MD, Oshlack A. A scaling normalization method for differential expression analysis of RNA-seq data. Genome Biol. 2010;11(3):R25. doi:10.1186/gb-2010-11-3-r25

23. Benjamini Y, Hochberg Y. Controlling the False Discovery Rate: a Practical and Powerful Approach to Multiple Testing. J R Stat Soc. 1995;57(1):289-300.

24. Shoemaker JE, Lopes TJ, Ghosh S, Matsuoka Y, Kawaoka Y, Kitano H. CTen: a web-based platform for identifying enriched cell types from heterogenous microarray data. BMC Genomics. 2012;13:460-71. doi:10.1186/1471-2164-13-460.

25. Team RDC. R: A Language and Environment for Statistical Computing. R Foundation for Statistical Computing: Vienna, Austria; 2010

26. Rozen S, Skaletsky H. Primer3 on the WWW for general users and for biology programmers. Methods Mol Bio. 2000;132:365-86.

27. Chiang HI, Swaggerty CL, Kogut MH, Dowd SE, Li X, Pevzner IY, et al. Gene expression profiling in chicken heterophils with Salmonella enteritidis stimulation using chicken $44 \mathrm{~K}$ Agilent microarray. BMC Genomics 2008:9:526-37. doi:10.1186/1471-2164-9-526.

28. Li X, Swaggerty CL, Kogut MH, Chiang HI, Wang Y, Genovese KJ, et al. Gene expression profiling of the local response of genetic chicken lines that differ in their susceptibility to Campylobacter jejuni colonization. PLoS One. 2010;5:e11827. doi:10.1371/journal.pone.0011827.

29. International chicken genome sequencing consortium. Sequence and comparative analysis of the chicken genome provide unique perspectives on vertebrate evolution. Nature. 2004;432:695-716.

30. Granucci F, Ferrero E, Foti M, Aggujaro D, Vettoretto K, Ricciardi-Castagnoli P. Early events in dendritic cell matura- tion induced by LPS. Microbes Infect. 1999;1(13):1079-84.

31. Luo C, Shen G, Liu N, Gong F, Wei X, Yao S, et al. Ammonia drives dendritic cells into dysfuction. J Immunol. 2014;193(3):1080-9.

32. Tan JK, O'Neill HC. Maturation requirements for dendritic cells in T cell stimulation leading to tolerance versus immunity. J Leukoc Biol. 2005:78(2):319-24.

33. Wu Z, Rothwell L, Young JR, Kaufman J, Butter C, Kaiser P. Generation and characterization of chicken bone marrow-derived dendritic cells. Immunology. 2010;129(1):133-45. doi:10.1111/j.1365-2567.2009.03129.x.

34. Liang J, Fu J, Kang H, Lin J, Yu Q, Yang Q. The stimulatory effect of TLRs ligands on maturation of chicken bone marrow-derived dendritic cells. Vet Immunol Immunopathol. 2013;155(3):205-10. doi:10.1016/j.vetimm 2013.06.014.

35. van Furth $R$, Cohn ZA, Hirsch JG, Humphrey JH, Spector WG, Langevoort HL. Mononuclear phagocytic system: new classification of macrophages, monocytes and of their cell line. Bull World Health Organ. 1972;47(5):651-8

36. Sallusto F, Lanzavecchia A. Efficient presentation of soluble antigen by cultured human dendritic cells is maintained by granulocyte/macrophage colony-stimulating factor plus interleukin 4 and downregulated by tumor necrosis factor-a. J Exp Med. 1994;179(4):1109-18.

37. Chomarat P, Banchereau J, Davoust J, Palucka AK. IL-6 switches the differentiation of monocytes from dendritic cells to macrophages. Nature Immunol. 2000;1(6):510-4.
38. Qureshi MA, Heggen CL, Hussain I. Avian macrophage: effector functions in health and disease. Dev Comp Immunol. 2000:24(2-3):103-19.

39. Klasing KC. Avian macrophages: regulators of local and systemic immune responses. Poult Sci. 1998;77(7):983-9.

40. Qureshi MA. Role of macrophages in avian health and disease. Poult Sci. 1998;77(7):978-82

41. Bombara CJ, Taylor RL. Signal transduction events in chicken interleukin-1 production. Poultry Sci. 1991;70(6):1372-80.

42. Davison TFA, Kaiser P. Advances in Avian Immunology Research. In: Klasing KC. Partial characterization of interleukin 1-like and tumor necrosis factorlike activities released from chicken macrophages. 1995. p. 151-159.

43. Bucy RP, Coltey M, Chen Cl, Char D, Le Douarin NM, Cooper MD Cytoplasmic CD3+ surface CD8+ lymphocytes develop as a thymusindependent lineage in chick-quail chimeras. Eur J Immunol. 1989;19(8):1449-55.

44. Yoder JA, Litman GW. The phylogenetic origins of natural killer receptors and recognition: relationships, possibilities, and realities. Immunogenetics. 2011;63(3):123-41. doi:10.1007/s00251-010-0506-4.

45. Vivier $\mathrm{E}$, Tomasello E, Baratin M, Walzer T, Ugolini S. Functions of natural killer cells. Nat Immunol. 2008;9(5):503-10. doi:10.1038/ni1582.

46. Sun H, Lu J, Liu L, Yang CY, Wang S. Potent and selective small-molecule inhibitors of CIAP1/2 proteins reveal that the binding of Smac mimetics to XIAP BIR3 is not required for their effective induction of cell death in tumor cells. ACS Chem Biol. 2014;9(4):994-1002. doi:10.1021/cb400889a.

47. O'Neill LAJ. Tampering with Toll-like receptor signaling. Cell. 2007;131(6):1039-41.

48. Medzhitov R, Janeway CJ. Innate immune recognition: mechanisms and pathways. Immunol Rev. 2000;173:89-97.

49. Kobayashi K, Inohara N, Hernandez LD, Galan JE, Nunez G, Janeway CA, et al. RICK/Rip2/CARDIAK mediates signaling for receptors of the innate and adaptive immune systems. Nature. 2002;416(6877):194-9.

50. Lu C, Wang A, Dorsch M, Tian J, Nagashima K, Coyle AJ, et al. Participation of Rip2 in lipopolysaccharide signaling is independent of its kinase activity. J Bio Chem. 2005;280(16):16278-83.

51. Laky K, Fowlkes BJ. Notch Signaling in CD4 and CD8 T Cell Development. Curr Opin Immunol. 2008:20(2):197-202. doi:10.1016/j.coi.2008.03.004.

52. Godfrey DI, Zlotnik A, Suda T. Phenotypic and functional characterization of c-kit expression during intrathymic T cell development. J Immunol. 1992;149(7):2281-5.

53. Ogawa M, Matsuzaki Y, Nishikawa S, Hayashi SI, Kunisada T, Sudo T, et al. Expression and function of c-kit in hemopoietic progenitor cells. J Exp Med. 1991;174(1):63-71.

54. Patel ES, Chang LJ. Synergistic effects of interleukin-7 and pre-T cell receptor signaling in human $\mathrm{T}$ cell development. J Biol Chem. 2012:287(40):33826-35

55. Liston A, Enders A, Siggs OM. Unravelling the association of partial T cell immunodeficiency and immune dysregulation. Nat Rev Immunol. 2008;8(7):545-58. doi:10.1038/nri2336.

56. Zhang R, Alt F, Davidson L, Orkin SH, Swat W. Defective signaling through the $\mathrm{T}$ - and B-cell antigen receptors in lymphoid cells lacking the vav proto- oncogene. Nature. 1995;374(6521):470-3.

57. Fischer KD, Zmuldzinas A, Gardner S, Barbacid M, Bernstein A, Guidos C. Defective T-cell receptor signalling and positive selection of Vav-deficient CD4+ CD8+ thymocytes. Nature. 1995;374(6521):474-7.

58. Appleby MW, Gross JA, Cooke MP, Levin SD, Qian X, Perlmutter RM. Defective T cell receptor signaling in mice lacking the thymic isoform of p59fyn. Cell. 1992;70(5):751-63.

59. Imamura Y, Oda A, Katahira T, Bundo K, Pike KA, Ratcliffe MJ, et al. BLNK binds active $\mathrm{H}$-Ras to promote $\mathrm{B}$ cell receptor-mediated capping and ERK activation. J Biol Chem. 2009;284(15):9804-13. doi:10.1074/jbc M809051200.

60. Refaeli Y, Young RM, Turner BC, Duda J, Field KA, Bishop JM. The B cell antigen receptor and overexpression of MYC can cooperate in the genesis of B cell lymphomas. PLoS Biol. 2008;6(6):e152. doi:10.1371/journal. pbio.0060152.

61. Nahar R, Ramezani-Rad P, Mossner M, Duy C, Cerchietti L, Geng H, et al. Pre-B cell receptor-mediated activation of BCL6 induces pre-B cell quiescence through transcriptional repression of MYC. Blood. 2011;118(15):4174-8. doi:10.1182/blood-2011-01-331181.

62. Mizuno T, Rothstein TL. B cell receptor (BCR) cross-talk: CD40 engagement creates an alternate pathway for BCR signaling that activates IKB kinase/ 
IKBa/NF-KB without the need for PI3K and phospholipase C gamma. J Immunol. 2005;174(10):6062-70.

63. Wienands J, Schweikert J, Wollscheid B, Jumaa H, Nielsen PJ, Reth M. SLP-65: a new signaling component in B lymphocytes which requires expression of the antigen receptor for phosphorylation. J Exp Med. 1998;188(4):791-5.

64. Goitsuka R, Fujimura Y, Mamada H, Umeda A, Morimura T, Uetsuka K, et al. $\mathrm{BASH}$, a novel signaling molecule preferentially expressed in B cells of the bursa of Fabricius. J Immunol. 1998;161(11):5804-8.

65. Wang $\mathrm{H}$, Lee $\mathrm{CH}$, Qi C, Tailor P, Feng J, Abbasi S, et al. IRF8 regulates B-cell lineage specification, commitment, and differentiation. Blood. 2008;112(10):4028-38. doi:10.1182/blood-2008-01-129049.

66. Alegre ML, Frauwirth KA, Thompson CB. T-cell regulation by CD28 and CTLA-4. Nat Rev Immunol. 2001;1:220-8.

67. King C. New insights into the differentiation and fuction of T follicular helper cells. Nat Rev Immunol. 2009;9:757-66. doi:10.1038/nri2644.

68. Wong CK, Ho CY, Ko FWS, Chan CHS, Ho ASS, Hui DSC, et al. Proinflammatory cytokines (IL-17, IL-6, IL-18 and IL-12) and Th cytokines (IFN-y, IL-4, IL-10 and IL-13) in patients with allergic asthma. Clin Exp Immunol. 2001;125(2):177-83.

69. Lalor SJ, Dungan LS, Sutton CE, Basdeo SA, Fletcher JM, Mills KHG. Caspase1-processed cytokines IL-1 $\beta$ and IL-18 promote IL-17 production by $\delta \gamma$ and CD4 T cells that mediate autoimmunity. J Immunol. 2011;186(10):5738-48. doi:10.4049/jimmunol.1003597.

70. Viallard JF, Pellegrin JL, Ranchin V, Schaeverbeke T, Dehais J, Longy-borsier $\mathrm{M}$, et al. Th1 (IL-2, interferon-gamma (IFN- $\gamma)$ ) and Th2 (IL-10, IL-4) cytokine production by peripheral blood mononuclear cells (PBMC) from patients with systemic lupus erythematosus (SLE). Clin Exp Immunol. 1999;115(1):189-95

71. Wang LH, Kirken RA, Yang XY, Erwin RA, DaSilva L, Yu CR, et al. Selective disruption of interleukin 4 autocrine-regualted loop by a tyrosine kinase inhibitor restricts activity of T-helper 2 cells. Blood. 2000;95(12):3816-22.

72. Luo $H$, Zhang $Y$, Zhang $Z$, Jin $Y$. The protection of MSCs from apoptosis in nerve regeneration by TGF $\beta 1$ through reducing inflammation and promoting VEGF- dependent angiogenesis. Biomaterials. 2012;33(17):4277-87.

73. Bergmann A, Steller H. Apoptosis, stem cells, and tissue regeneration. Sci Signal. 2010;3(145):1-16.

74. Aachoui Y, Sagulenko V, Miao EA, Stacey KJ. Inflammasome-mediated pyroptotic and apoptotic cell death, and defense against infection Curr Opin Microbiol. 2013;16(3):319-26.

\section{Submit your next manuscript to BioMed Central and take full advantage of:}

- Convenient online submission

- Thorough peer review

- No space constraints or color figure charges

- Immediate publication on acceptance

- Inclusion in PubMed, CAS, Scopus and Google Scholar

- Research which is freely available for redistribution 